\title{
A new analysis of the global detrital zircon record with inferences regarding the growth and rise of the continental crust
}

\author{
JESSE R REIMINK ${ }^{1}$, JOSHUA H.F.L. DAVIES ${ }^{2}$ AND \\ ALESSANDRO IELPI ${ }^{3}$ \\ ${ }^{1}$ Pennsylvania State University \\ ${ }^{2}$ Université de Québec à Montréal \\ ${ }^{3}$ Laurentian University \\ Presenting Author: jreimink@psu.edu
}

Contrasting hypotheses have been formulated regarding the rise of continental crust above sea level. Particular attention has been paid to the periods near the end of the Archean, as some geochemical and geological evidence suggests a change in continental freeboard near $2.4 \mathrm{Ga}$.

Here, we use the detrital-zircon age compilation of [1], which includes $>680,000$ individual zircon $\mathrm{U}-\mathrm{Pb}$ ages. We analyze these data in two ways; first, by using a novel sample-based strategy that calculates the zircon age distribution statistics from individual sedimentary samples, and secondly by using a more conventional approach that divides individual analyses by age group only. After filtering for discordance and a minimum number of zircon analyses from each sediment, our analysis interrogates 4,248 samples with depositional ages ranging from $3.4 \mathrm{Ga}$ to modern.

A major conclusion that emerges from our analysis is that mature sediments, defined here as having a diverse zircon age distribution with zircon ages near the age of the Earth at the time of deposition, appear on Earth very soon after sediments are preserved globally, near $\sim 3.0$ Ga. Combined with existing geologic evidence, we interpret this results to be a signature of large-scale continental freeboard increase, with continents becoming globally emergent near $3.0 \mathrm{Ga}$ and rising to modern levels by $\sim 2.4 \mathrm{Ga}$.

[1] Puetz, S. J., \& Condie, K. C. (2019). Geoscience Frontiers, 10(4), 1305-1326. 